\title{
ENHANCEMENT OF STUDENT LEARNING THROUGH SELF-REFLECTION
}

\author{
Laura Soriano, Danny Mann, Marcia R. Friesen \\ Faculty of Engineering, University of Manitoba \\ Danny.Mann@umanitoba.ca, Marcia.Friesen@umanitoba.ca
}

\begin{abstract}
-
Recent accreditation requirements by the Canadian Engineering Accreditation Board (CEAB) have forced engineering educators to focus on the outcomes of their teaching efforts. Faculty members are rapidly gaining expertise in the assessment of the 12 graduate attributes, and it is envisioned that emphasis on outcomes-based assessment will improve both the quality of the overall curriculum and individual course instruction.
\end{abstract}

Nevertheless, the ultimate goal of any educational activity is to foster student learning. It is anticipated that students will gain a better understanding of the graduate attributes being covered in their courses if they are given the opportunity to self-reflect upon their educational experiences and achievements.

The portfolio is the tool most often used to achieve this goal of self-reflection. A project has been undertaken in the Department of Biosystems Engineering at the University of Manitoba to assess the impact of self-reflection on student learning. During the fall of 2018, a series of voluntary workshops were organized

i) to introduce Biosystems Engineering students to the purpose and art of selfreflection,

ii) to describe self-reflection in the context of the Canadian Engineering Accreditation Board graduate attributes,

iii) to introduce the e-portfolio tool,

iv) to develop the skill of self-reflective writing, and

v) to demonstrate the link between e-portfolio development and career success.

The purpose of the paper is to describe the workshop series, the focus groups that followed the workshop series, and the theoretical framework within which the work is positioned.
Keywords: e-portfolios; self-reflection; graduate attributes; student-centered learning

\section{INTRODUCTION}

This work examines the role of e-portfolios (electronic portfolios) as a self-reflection tool in engineering education. This paper reports on the progress and preliminary findings of a study designed to examine students' perceptions and experiences with self-reflection relative to e-portfolios and their engineering studies more generally.

A portfolio is a multifaceted educational tool that can range from the simple collection of selected work by the student to a complex learning strategy to foster selfreflection. A portfolio can also be used as an alternative assessment method by which students can demonstrate evidence of the Canadian Engineering Accreditation Board graduate attributes.

The idea of implementing e-portfolios as a tool for learning, however, is not new. Paulson et al. (1991) [1] defined a portfolio as a "purposeful collection of student work that exhibits the student's efforts, progress, and achievements. The collection must include student participation in selecting contents, the criteria for selection, the criteria for judging merit, and evidence of self-reflection." (p. 60).

When creating an e-portfolio, it is inevitable for the student to apply some sort of criteria when choosing the content for the portfolio. The content of a portfolio can be selected arbitrarily by the student based on what the student considers to be an achievement or an interesting learning activity. However, Carmean et al. (2006) [2] suggest that "to give the portfolio purpose and structure, it should be organized around standards or benchmarks and reflect the learner's growth toward those standards." (p.37). The simple act of collecting and organizing student work does not guarantee that the student will engage in the selfreflection process, yet, establishing clear criteria to select 
content material such as graduate attributes benchmarks, is a step forward towards self-reflection. This can encourage students to think of their work within the accreditation criteria framework.

The use of e-portfolios in engineering education is also an appealing concept to administrators wishing to promote active learning. Active learning seeks to directly engage students in the learning process as opposed to learning by passive means such as listening. [3] It requires students to $d o$ and consequently think by applying higher order thinking skills such as metacognition and critical thinking [4] [5]. Higher order thinking skills can be incorporated through various methodologies including writing and reflecting, discussing, and problem solving.

The e-portfolio is inherently a student-centered approach and can be used to demonstrate the graduate attribute criteria. A student-centered approach allows switching the responsibility of learning from the teacher to the student by involving the student in the learning process. [6]

The graduate attributes criteria support an education that is holistic or integrated by incorporating attributes such as ethics and equity, the impact of engineering on society and the environment, professionalism and life-long learning. Holistic education can be defined as education draws knowledge from several other fields like sociology, anthropology, psychology and economics. It is conceived that a student-centered approach is a more suitable approach to teach and learn the graduate attributes since it allows students to identify their positionality in society and integrate personal experiences that can help them better understand the complexity of interdisciplinary concepts.

One of the main objectives of the workshop series implemented in the fall of 2018 in the Department of Biosystems Engineering at the University of Manitoba, was to promote the use of e-portfolios that were organized based on accreditation criteria, establishing the 12 engineering graduate attributes as benchmarks of learning. It is intended that the e-portfolio will reflect the learner's growth towards the graduate attributes.

In recent work, Fasina et al. (2015) [7] wrote an article in Resource magazine that highlighted the benefits of incorporating e-portfolios into student learning. Their article described experiences using e-portfolios for Biosystems engineering students at Auburn University's Department of Biosystems Engineering. This experience is particularly relevant at the University of Manitoba given that both learning experiences and career development challenges are similar.
Earlier, Knott et al. (2004) [8] described a pilot eportfolio project at Virginia Tech. Members of Virginia Tech identified the e-portfolio as an ideal tool to support/enable student reflection. The e-portfolio was also identified as an excellent tool for the professional development of students [8].

Most agree that the process of developing a portfolio is an excellent educational activity that enhances the understanding of the curriculum by the student [7][8]. The challenge often lies on how to implement best the use of portfolios that do not create any interference with the delivery of the program itself, creating an additional burden that has already been placed on academics as a result of the newly-imposed accreditation requirements by the Canadian Engineering Accreditation Board.

Although authors of the Fasina et al. (2015) study indicated that they intended to incorporate e-portfolios into an increasing number of courses based on the benefits that have been observed from their pilot study, it can be argued that an environment in which students can engage in learning because they "want to" rather than "have to", is a more genuine and effective approach to implementing the usage of reflective e-portfolios.

A voluntary approach towards implementing the eportfolio is based on the idea of intrinsic motivation which can help students gain autonomy, self-awareness and work towards self-regulated learning [9]. Intrinsic motivation does not rely on external pressures, but it is driven instead by self-determination and the feeling that one is improving or acquiring new skills by engaging in the task. [10] Intrinsic motivation then requires students to have a degree of control (autonomy) over their educational outcomes to the extent that they believe they can be effective agents in improving their abilities (self-efficacy) and mastering new knowledge. [10]

The objective of the present paper is to describe the purpose and rationale behind the implementation of eportfolios as a learning tool in engineering education and to describe the performance of the workshop series as an early stage initiative to promote the usage of e-portfolios.

\section{BACKGROUND \& LITERATURE}

\subsection{E-portfolios and self-reflection}

The e-portfolio as an educational tool originates from the idea of the learning journal. The learning journal, in its literary form, falls between the definition of a logbook and a diary [11]. Learning journals help students to focus on the process of learning rather than on established end goals [12]. 
The use of journals or logbooks is a practice already in place and embedded in the engineering curriculum at the University of Manitoba. However, the use of a journal in the engineering design courses is emphasized as a legal document for the purposes of claiming a patent, to avoid a lawsuit in the dispute of idea ownership or to provide the underlying data and analysis of a design. With this in mind, the purpose of keeping a journal in the engineering design courses is primarily to keep a record of the individual and team-work done in a group project towards the design of technology or the solution to a problem. It is stated that the journal must be a hardcover, bound notebook from which the pages cannot be turned easily. All the pages must be numbered and the use of white-out is not allowed. Entries must be recorded on a daily basis with the date and time labeled in order for it to be considered a legal document.

The learning or reflective component is largely absent from the activity of keeping a journal in the engineering design or technical communication courses, except to the extent that which a student may additionally use it as such. Journals in the engineering context are not typically used as learning tools, but rather as record-keeping documents to demonstrate a process for legal purposes.

When keeping a record of their work, students do not do so with the mindset of reflecting on their learning. However, this is not the case when it comes to journaling in the broader field of education. The use of journals as a learning method emerged from research on the correlation between "writing and the development of thinking" ( $\mathrm{p}$. 306) [13]. It is the specific correlation between writing and thinking that makes journals, like e-portfolios, tools for reflection and active learning. The element of reflection or metacognition differentiates the e-portfolio from a simple collection of documents turning it into a potential learning tool.

The learning journal seeks to engage students in the learning process and to foster reflection. Similarly, eportfolios are educational tools that intend to promote a complex understanding of a subject [14]. By "complex understanding" it is meant the implementation of higher order thinking skills such as critical thinking and metacognition. It is important to consider the value of higher order thinking skills and its applications within the engineering and broader social context to understand the relevance of learning journals and e-portfolios.

A more recent notion is the use of e-portfolios to support employability claims by providing evidence of knowledge and skills through an inventory of documents [9]. As mentioned before, e-portfolios are multifaceted and can be used for the purpose of reflection, communication with employers, or as an alternative assessment method for purposes of accreditation. It is therefore important to clarify the purpose of e-portfolios and be careful as to how these ideas are presented to students.

Nevertheless, the need of administration for assessment arising from accreditation demands and the appeal of using e-portfolios as a marketing tool for employment purposes, obscures the use of e-portfolios as a learning method closely correlated with the art of thinking. Barret (2005) [15] attempts to provide a solution for the multidimensionality of e-portfolios:

"Portfolios should support an environment of reflection and collaboration. It is a rare system that supports those multiple needs. That is why I often advocate for three interconnected systems: an archive of student work, an assessment management system to document achievement of standards, and an authoring environment where students can construct their own electronic portfolios and reflective, digital stories of learning" (p. 14)

\subsection{Self-reflection and student learning}

Self-reflection in engineering education is commonly associated with experiential learning. Experiential learning is defined as the process of learning through experience. For the learning component to occur during experiential learning, reflection is a requirement. So experiential learning can be reworded as "learning through reflection on doing." [16]

Within an engineering education context, self reflection is usually framed as “... an intentional and dialectical thinking process where an individual revisits features of an experience with which he/she is aware and uses one or more lenses in order to assign meaning(s) to the experience that can guide future action (and thus future experience)." [17]

The notion of self-reflection with the goal of examining individual action is largely influenced by the work of four theorists: Dewey, Kolb, Schon and Mezirow [17]. Turns et al. (2014) summarize the work of the four theorists as follows:

- Dewey theorizes that "experience has the potential to lead to learning."

- Kolb further adds to the knowledge of reflection by contributing with the Experiential Learning Model.

- Schon establishes a link between reflection and professional activity

- Mezirow emphasizes the critical component of reflection for the purposes of questioning assumptions or one's framework of thought. 
It has been previously stated that reflection of one's own action or self-reflection is required for the learning component of experiential learning. Experiencing something alone does not guarantee learning. The process by which one acquires knowledge of the self is metacognition.

Metacognition can be defined as "knowledge of one's knowledge, processes, and cognitive and affective states; and the ability to consciously and deliberately monitor and regulate one's knowledge, processes, and cognitive and affective states" [18] Metacognition is linked to experiential learning through self-reflection, but its relevance extends beyond the realm of learning into realistic scenarios in which a lack of awareness of one's biases or assumptions can lead to errors. [19] In engineering, this kind of errors are often illustrated through real case scenarios in which assumptions or a lack of awareness of assumptions has led to accidents. [20]

As previously stated, metacognition is essential to the learning process in experiential learning. However, experiential learning can pose issues given that experience is limited to the personal realm in which individual actions are often considered on its own without considering any context. This can cause students to become overcritical of their performance [21] Smith proposes a theoretically informed model of self-reflection which encompasses learning and assessment of both the self and social systems, along with reflection that is not only personal but interpersonal, contextual and critical. [21]

In this paper, it is discussed that a constructivist approach in which the social system is considered, can make of self-reflection a more appropriate learning tool. Particularly, self-reflection from a constructivist perspective could be incorporated in engineering education as a means to introduce graduate attributes that are of an "interdisciplinary nature" such as "the impact of engineering on society and the environment," "ethics" and "professionalism." These graduate attributes are characterized by situating learning within a broad social and cultural context.

It is necessary to consider the role self-reflection has played in history and the philosophy of science to adopt a constructivist approach. From the notions of Plato and Thomas Aquinas to Rene Descartes, self-reflection seems to emerge largely from "the quest for truth" or epistemology [22].

Epistemology or the Theory of Knowledge, inquiries into the nature of knowledge and the justification of belief [23]. The justification of beliefs is the foundation of Rationalism, which in philosophy is the epistemological view that knowledge is acquired by reason and not merely by perception [22]. Empiricism, on the other hand, is the theory that states that knowledge comes only or primarily from sensory experience [22].

Engineering, like the trades and technology, is a field which is strongly influenced by notions of empiricism and positivism. [24] Due to the heavy influence of empiricism, the activity of examining the beliefs and assumptions that underlie one's thinking or individual actions (selfreflection), is unusual and unheard of within an engineering context. In contrast, students in the Humanities, are often required to justify the premises of their beliefs when making a point or providing an argument; reflection is therefore not unusual in the context of the Arts and the Humanities.

With the many problems the world faces today such as the ecological crisis, overpopulation, and unsustainable development, it is important that engineers attain a critical mindset that helps them challenge the culture and social structures in place which shape the engineer's mindset and impacts the way in which technologies are designed and developed in the market with the aim to provide engineering solutions that are conscientious.

From the lens of critical pedagogy: "Knowledge does not transcend culture, history or social structure." (p.235) [25] Conversely, "the complexity of the educational process cannot be understood outside of the social, historical, philosophical, cultural, economic, political, and psychological contexts that shape it." (p. 235) [25]

The University of Waterloo Centre for Teaching Excellence provides a contextualized definition of selfreflection that goes beyond what self-reflection in experiential learning can offer:

\begin{abstract}
"Without reflection, experience alone might cause us to "reinforce stereotypes..., offer simplistic solutions to complex problems and generalize inaccurately based on limited data" (Ash \& Clayton, 2009, p.26)." [26]

"Engaging in critical reflection, however, helps us articulate questions, confront bias, examine causality, contrast theory with practice and identify systemic issues all of which helps foster critical evaluation and knowledge transfer (Ash \& Clayton, 2009, p. 27)." [26]
\end{abstract}

\section{METHODOLOGY}

This research project aims to study the impact of selfreflection on learning in relation to the $\mathrm{CEAB}$ graduate attributes. Students' perceptions and attitudes in regard to the process of engaging in the creation of an academic, reflective e-portfolio were explored. 
To carry out this investigation, it is necessary that students engage first in the process of self-reflection. For this purpose, a workshop series was organized to introduce students to the creation of a reflective e-portfolio for academic purposes. Second, focus groups were carried out to explore the actual experiences of students that attended the workshops or had engaged in the process of selfreflection through other mediums such as journaling or web-blogging.

Focus groups explored how students engaged in the process of self-reflection, what some of the perceived barriers were in this process, and in which ways students associated their rationale with their personal experiences or their education. These data are significant to understand the value of e-portfolios as a learning method in engineering education and to provide insights on how to successfully structure and promote the usage of nonmandatory e-portfolios in the Department of Biosystems Engineering.

Since the objective of this study was to explore and understand the experiences and views of students rather than describe or quantify them, it was determined that qualitative methods of study using theory-based procedures are more suitable for exploring such questions. It can be argued that qualitative research relies on scientific observation to gather information that is not quantifiable. [27].

\subsection{Workshop series}

Five workshops were delivered to Biosystems Engineering students in fall 2018. These workshops were designed to introduce students to the concept of selfreflection and the creation of an e-portfolio; they were voluntary based on the premises of intrinsic motivation and self-directed engagement. As mentioned previously, an environment in which students can engage in learning because they want to rather than have to, seems to be a more genuine and effective approach to implementing the usage of reflective e-portfolios. It was considered that students would engage in the process as means to gain autonomy, self-awareness and strengthen an identification with their career given that the e-portfolio focuses on individual achievements and students are encouraged to identify personal experiences relevant to their learning [9]. It was also thought that students would be strongly motivated to invest their time to reflect on their educational experiences and achievements if the result is an e-portfolio that can assist with career development. Five workshops were organized and were delivered by several faculty members and professional staff in the Faculty of Engineering.
3.1.1. Workshop \#1: The Purpose \& Art of SelfReflection. The importance of self-reflection and critical reflection were discussed with an emphasis on personal growth, development and self-expression. The workshop was conducted based on the definition of reflection provided by Rogers (2001) [28]. Based on seven theoretical approaches (Langer,1989; Dewey, 1933; Seibert and Daudelin, 1999; Loughran, 1996; Boud et al., 1985; Schon 1983; Mezirow,1991) Rogers (2001) concludes that reflection is defined as a cognitive and affective process or activity that:

(1) "requires active engagement on the part of the individual;

(2) is triggered by an unusual or perplexing situation or experience;

(3) involves examining one's responses, beliefs, and premises in light of the situation at hand; and

(4) results in the integration of the new understanding into one's experience."

Based on Hiemstra (2001) [29]. The potential benefits of self-reflection were also introduced:

Table 1: Benefits of self-reflection Hiemstra, R. (2001)

\begin{tabular}{|c|c|}
\hline $\begin{array}{c}\text { Benefits of self- } \\
\text { reflection }\end{array}$ & Description \\
\hline $\begin{array}{l}\text { Personal Growth and } \\
\text { Development }\end{array}$ & $\begin{array}{l}\text { - Integration of life } \\
\text { experiences with formal } \\
\text { learning } \\
\text { - Mental development } \\
\text { stimulation } \\
\text { - New insight breakthroughs } \\
\text { - Awareness of thoughts and } \\
\text { feelings }\end{array}$ \\
\hline $\begin{array}{l}\text { Intuition and Self- } \\
\text { Expression }\end{array}$ & $\begin{array}{l}\text { - Self-discovery ability } \\
\text { - "Learning to trust that inner } \\
\text { voice." } \\
\text { - Increase of self-confidence }\end{array}$ \\
\hline Problem Solving & $\begin{array}{l}\text { - Hypothetically solving a } \\
\text { problem integrating personal } \\
\text { experiences }\end{array}$ \\
\hline Stress Reduction & $\begin{array}{l}\text { - A useful technique for } \\
\text { psychological healing }\end{array}$ \\
\hline
\end{tabular}

3.1.2. Workshop \#2: Self-Reflection in the Context of the CEAB Graduate Attributes. Students were provided with an in-depth overview of each of the CEAB graduate attributes. Students were also guided into recognizing where each of these attributes is being developed within the Biosystems Engineering program.

\subsubsection{Workshop \#3: Introduction to the e-Portfolio tool}


Students were introduced to the e-portfolio tool as an educational tool that can help students reflect on their learning and keep a record of all their academic knowledge and work experience obtained during university, co-op terms, and extracurricular activities.

The e-portfolio was also presented as a powerful tool for students to market themselves when looking for a job after graduation or when interviewing for a co-op position as academic knowledge and experience logged into the eportfolio can be easily displayed and shared with others. The advantages and disadvantages of four software platforms (Seelio, Google Sites, Weebly, Wix) were presented to students based on the following criteria:

- Aesthetics: look and feel of the page including background colors, fonts, layouts, and designs

- Ease of creating the e-portfolio: how easy it is to grasp the functioning of the software to create a page

- Customization: the option to modify and design the page to suit individual preferences

- Specific functionality: whether the site is generic (website builder) or exclusive to design e-portfolios

- Storage capacity and multimedia support: How much content can be uploaded and what kind of files (.dmg, .mov, .pdf etc.) can be displayed in the page

\subsubsection{Workshop \#4: Development of an e-Portfolio}

This workshop emphasized reflective writing as a way to make connections between learning \& practice. It was suggested that reflection could be useful to explicitly identify competencies that characterize a learning experience such as teamwork or communication skills. Conversely, reflection can also be applied to recognize specific experiences that contribute to the development of those competencies. It was also discussed that a useful way to structure the e-portfolio is by examining the links between Canadian Engineering Accreditation Board Graduate Attributes to Employability Skills 2000+ Framework

3.1.5. Workshop \#5: Demonstrating and Articulating your Skills and Experience for Career Success using an e-Portfolio. In this workshop, the mechanics of developing an e-portfolio was discussed, to help students gain the confidence to articulate competencies as they relate to engineering practice. Students were provided with strategies on how to connect their e-portfolio with their resume through story-telling. Story-telling is an activity that requires reflection on past experiences. The process of creating an e-portfolio can assist in finding and selecting stories that can be useful when being interviewed by an employer.
Written feedback from students that participated in these voluntary workshops at the end of the final workshop was positive. Many students emphasized what they had learned during each of the workshops.

\subsection{Focus Group Research}

Using the workshop series as the context to introduce students to self-reflection, voluntary students were recruited from the workshop attendees to participate in focus groups. The focus groups were held in Winter 2019, the academic term following completion of the workshop series was carried out. Out of the 23 students that attended the workshops, five students participated in two focus group discussions. The sessions were audio-recorded and transcribed. A script of the discussion with individual comments was sent to each participant for member checking as a way to validate student's comments and perceptions.

Focus groups are guided group discussions about a topic of interest and ways of finding out students' thoughts and experiences about a topic. In this case, the discussion was guided towards the topics of self-reflection and the development of an e-portfolio.

The discussion was grounded on the general student experience in the Faculty of Engineering in which students first engaged in discussing their educational experience in engineering, in a broad sense, and then the conversation was guided towards the discussion of the motivation for attending the workshops. The conversation was not compartmentalized into the exclusive discussion of eportfolios, but fluctuated from a discussion of engineering education, the Biosystems program, and feelings and thoughts the students hold about their careers.

The reason for engaging students in a rather broad conversation was to instill confidence in the students. This was necessary given the fact that students had not yet begun to complete an e-portfolio. An e-portfolio is an ongoing process most likely to be achieved over the period of an academic year through consistent entries. However, it is of interest to know what students perceive as barriers or motivators for students to start an e-portfolio and how students intended to incorporate the graduate attributes or other concepts learned at the workshops.

Focus group questions and probes were developed around the themes of students' feelings and expectations of post-secondary education and engineering studies, in particular, their understanding and stance toward CEAB graduate attributes, their motivation and expectations for participating in the workshop series, and their understanding of self-reflection. 


\section{DISCUSSION}

Some of the lessons learned from the implementation of the workshop series are that while students seem to find value in having an e-portfolio for employment purposes, workshop attendance did not guarantee the completion of an e-portfolio or engagement in the self-reflection process. Students expressed that they were expecting to work towards a finished product by the end of the series. They also perceived developing an e-portfolio as an activity that required significant effort, and thus a challenge to take on if it was not associated directly with a course or program requirements. These feelings may arise from being unfamiliar with the process itself of creating the eportfolio.

At the time of writing, the focus group data have been collected and preliminarily categorized; however, deeper analysis is required in order to report complete findings. Initial insights emerging from the discussion of student experiences in engineering can be interpreted through the lens of social theory. Through this lens, the data implied a low level of reflexivity in the sense that students fail to recognize forces of socialization that shape their experiences and academic outcomes in their responses.

Students also seemed to express the "negative selfregulatory function" of self-reflection as described by Smith (2011) [21] when discussing their thoughts by making comments such as "[self-reflection] makes me think that I should focus on how I can be better."

Reflection is limited to personal actions, and so, students may risk falling into "self-conscious cynicism" becoming overcritical of their own performance [21]. It is very important to address the "negative self-regulatory function" of critical reflection since negative feelings about one's performance can hinder learning and the will to persist [21].

It is important to emphasize that self-reflection must be contextual and critical (constructive) to avoid falling into self-conscious cynicism. By considering the social context and adopting a critical mindset, one can achieve an understanding of the factors that influence one's learning. This is supported by the constructivist view of learning which argues that learning is situational: "meaning is a product of activity and the culture and context in which that activity occurs (Brown \& Palincsar, 1989; Brown, Collins, \& Duguid, 1989; Lave \& Wenger, 1994)." (126) [5]

A constructivist perspective requires students to evaluate the context of their learning and to challenge the prefabricated meaning of information that influences their thinking [5]. The role of self-reflection as a learning strategy, from this perspective, is then to question or justify beliefs that emerge largely from social structures. In engineering education, self-reflection can be used as a learning strategy to incorporate $\mathrm{CEAB}$ outcomes such as:

"Impact of engineering on society and the environment: An ability to analyze social and environmental aspects of engineering activities. Such ability includes an understanding of the interactions that engineering has with the economic, social, health, safety, legal, and cultural aspects of society, the uncertainties in the prediction of such interactions; and the concepts of sustainable design and development and environmental stewardship."[30]

"Professionalism graduate attribute: An understanding of the roles and responsibilities of the professional engineer in society, especially the primary role of protection of the public and the public interest." [30]

"Life-long learning graduate attribute: An ability to identify and to address their own educational needs in a changing world in ways sufficient to maintain their competence and to allow them to contribute to the advancement of knowledge" [30]

The challenge remains on how to promote selfreflection in engineering in a way that is autonomous and is driven by intrinsic motivation rather than the implementation of this tool in a coercive way such as through mandatory assignments.

\section{CONCLUSION AND FUTURE WORK}

This paper reports on a work in progress. The data will be further analyzed through the various theoretical lenses to provide a comprehensive analysis of the project and to provide insights as to how best incorporate the reflective learning component in engineering education.

\section{Acknowledgements}

Dr. Jillian Seniuk Cicek and Lynda Peto contributed to the workshop series.

\section{References}

[1] Paulson, F. Leon, Pearl R. Paulson, and Carol A. Meyer. "What makes a portfolio a portfolio." Educational leadership, vol. 48:5, pp. 60, 1991. Available as of March 25, 2019, from: https://web.stanford.edu/dept/SUSE/projects/ireport/ar ticles/eportfolio/what $\% 20$ makes $\% 20 \mathrm{a} \% 20$ portfolio $\% 2$ 0a\%20portfolio.pdf

[2] Carmean, Colleen, and Alice Christie, Handbook of Research on ePortfolios: ePortfolios: Constructing meaning across time, space, and curriculum. IGI Global, 2006. pp. 33-43. \{ISBBN: 1-59140-891-1\} 
[3] Bonwell, Charles C., and James A. Eison. Active Learning: Creating Excitement in the Classroom. ASHE-ERIC Higher Education Report No. 1, 1991 \{ISBN:20036-1183, 1991\}

[4] Bean, John C. Engaging ideas: The professor's guide to integrating writing, critical thinking, and active learning in the classroom. John Wiley \& Sons, 2011. \{ISBN: 978-0-470-53290-4\}

[5] Renkl, A., Atkinson, R. K., Maier, U. H., \& Staley, R. (2002). "From example study to problem solving: Smooth transitions help learning." Journal of Experimental Education, 70 (4), 293-315.

[6] Iversen, A.-M., Pedersen, A. S., Krogh, L., \& Jensen, A. A. (2015). Learning, Leading, and Letting Go of Control: Learner-Led Approaches in Education. $S A G E$ Open. https://doi.org/10.1177/2158244015608423

[7] Fasina, O., Srivastava, P., Dougherty, M., Adhikari, S., McDonald, T., Taylor, S., \& Marshall, M. "Incorporating ePortfolios into Student Learning." Resource Magazine, vol. 22(6), pp. 10-12, 2015.

[8] Knott, T. W., V. K. Lohani, O. H. Griffin Jr, G. T. Loganthan, G. T. Adel, and T. M. Wildman. "Bridges for engineering education: Exploring ePortfolios in engineering education at Virginia Tech." in Proc. ASEE American Society for Engineering Education Annual Conference, age, vol. 9, pp.1, 2004.

[9] Hartnell-Young, Elizabeth. Handbook of Research on ePortfolios: ePortfolios for knowledge and learning. IGI Global, 2006. pp.125-134. \{ISBN: 1-59140-891-1\}

[10] Deci, Edward L.; Ryan, Richard M.. Intrinsic motivation and self-determination in human behavior. Springer US, 1985 \{ISBN 9781489922717$\}.$

[11] E. Hedlund, Dalva, Tanis C. Furst, and Kathryn T. Foley. "A Dialogue with Self: The Journal as an Educational Tool." The Journal of Humanistic Education and Development 27. 1989 https://doi.org/10.1002/j.2164-4683.1989.tb00166.x.

[12] Yinger, Robert. "Journal writing as a learning tool." The Volta Review, 1985.

[13] Haapaniemi, Tommi, and Pasi Karvonen. Handbook of Research on ePortfolios: Supporting the Portfolio Process with ONNI-The Learning Journal. IGI Global, 2006. pp. 305-312. \{ISBBN: 1-59140-891-1\}

[14] Farrell, Orna, and Aidan Seery. "'I am not simply learning and regurgitating information, I am also learning about myself": learning portfolio practice and online distance students." Distance Education, vol. 40.1, pp. 76-97, 2019.

[15] Barrett, Helen C, White Paper Researching Electronic Portfolios and Learner Engagement. 2005, 26 pp. Available as of March 25, 2019, from: http://google.electronicportfolios.com/reflect/whitepap er.pdf
[16] Felicia, Patrick, ed.Handbook of Research on Improving Learning and Motivation through Educational Games: Multidisciplinary Approaches: Multidisciplinary Approaches. IGI Global, 2011.

[17] Turns, Jennifer A., et al. "Integrating reflection into engineering education." in proceedings of the ASEE Annual Conference and Exposition, ACM, Vol. 35 2014.

[18] Hacker, D.J. J. Dunlosky and A.C. Graesser Metacognition in Educational Theory and Practice Taylor and Francis New York, 1998

[19] Medina M.S. A. N. Castleberry and A. M. Persky "Strategies for Improving Learner Metacognition in Health Professional Education" Am J Pharm Educ., vol 81 no. 4 Article 78, 2017

[20] Casey, Steven Michael. The atomic chef: And other true tales of design, technology, and human error. Aegean, 2006.

[21] Smith, E. "Teaching critical reflection." Teaching in Higher Education, vol 16:2, pp. 211-223, 2011.

[22] Pojman, Louis P, What can we know? An introduction to the theory of knowledge. Wadsworth Publishing Company, 1995, pp. 337 \{978-0190254773\}

[23] Steup, Matthias. "Epistemology." (2005). The Stanford Encyclopedia of Philosophy. Available as of May 5, 2019, from: https://plato.stanford.edu/entries/epistemology/

[24] Casey, Steven Michael. The atomic chef: And other true tales of design, technology, and human error. Aegean, 2006.

[25] Denzin, Norman K., and Yvonna S. Lincoln, eds. The Sage handbook of qualitative research. Sage, 2011.

[26] Centre for Teaching Excellence, University of Waterloo on Critical Reflection. Available as of March 25, 2019, from: $\quad$ https://uwaterloo.ca/centre-for-teachingexcellence/teaching-resources/teaching-tips/planningcourses-and-assignments/course-design/criticalreflection

[27] Babbie, Earl, The Basics of Social Research, Belmont, California: Wadsworth Cengage 2014 (6th ed.). 304 pp. \{ISBN: 9781133594147\}

[28] Rogers, Russell R. "Reflection in higher education: A concept analysis." Innovative higher education, vol. 26:1, pp. 37-57, 2001.

[29] Hiemstra, Roger. "Uses and benefits of journal writing." New directions for adult and continuing education, vol. 90, pp. 19, 2001.

[30] Engineers Canada "A Guide to Outcomes-based Criteria," p. 35. Available as of March 25, 2019, from: https://engineerscanada.ca/sites/default/files/draf $\mathrm{t}$ program visitor_guide v1.25.pdf 